\title{
Enhancing of Cotton Fabric Antibacterial Properties by Silver Nanoparticles Synthesized by New Egyptian Strain Fusarium Keratoplasticum A1-3
}

\author{
Asem A. Mohmed ${ }^{2 *}$, Amr Fouda ${ }^{1}$, Mamdoh S. Elgamal', Saad EL-Din Hassan', \\ Tharwat I. Shaheen ${ }^{2}$ and Salem S. Salem ${ }^{1}$ \\ ${ }^{1}$ Department of Botany and Microbiology, Al-Azhar University, Cairo, Egypt. \\ ${ }^{2}$ National Research Center (Scopus affiliation ID 60014618), Dokki-Giza, Cairo, Egypt.
}

\begin{abstract}
CPECTRAL analysis of biogenic silver nano-particles (AgNPs) produced by Fusarium keratoplasticum A1-3 showed absorption at $400 \mathrm{~nm}$ which is used as a monitor for the formation of silver nanoparticles.TEM analysis indicated the formation of spherical AgNPs in size range from 6 to $36 \mathrm{~nm}$. The band at $1650.13 \mathrm{~cm}^{-1}$ in FTIR analysis refers to the binding vibrations of amide I band of protein with $\mathrm{N}-\mathrm{H}$ stretching band.XRD pattern of Ag-NPs indicated silver Ag crystalline phase indexed; the particle size of the so obtained AgNPs was poly dispersed mixture with diameter average of 54.33 (92.7\%) with Zeta potential (mV) -23.7. AgNPs were applied to enhance antibacterial properties of cotton fabric with $86 \%$ and $93 \%$ growth reduction of test pathogenic bacterial strains.
\end{abstract}

Keywords: Fungi, Silver nano-particles, Spectroscopy, FTIR, XRD and Cotton fabric.

\section{Introduction}

The use of nanoparticles in the textile industry has increased rapidly. The application of nanoparticles to textile materials has been the object of several studies to produce finished fabrics with different performances $[1,2]$.

Silver nanoparticles are applied to textiles for their strong antimicrobial activity against pathogenic bacteria which attached to clothes; improve the clinical dressing and potential uses in various medical applications [3-5].

Nanotechnology and nanofabrication have opened their doors to a world of metal nanoparticles synthesis with easy preparation protocols, less toxicity and a wide range of applications according to their size and shape. Metal nanoparticles of desired size and shape have been obtained successfully using living organisms [6].

Fungi have been widely used for the biosynthesis of nanoparticles. Recently, fungi have been attracting more attention for the synthesis of different types of nanoparticles [7].

Several microorganisms have been found to be capable of synthesizing intra or extra cellular inorganic nanocomposites [8]. The present study aims to biosynthesis of AgNPs by biological methods and utilizes that nanoparticles in finishing of cotton fabric to enhance its antibacterial properties.

\section{Materials and methods}

Isolation and identification of fungal strain

Fusarium keratoplasticum A1-3was isolated from soil sample collected from Elcock company soil, Eltibeen, Helwan, Egypt (GPS N: 2978 $019 \mathrm{E}: 3130$ 247). About $1.0 \mathrm{~g}$ of soil sample was mixed with sterile distilled water and plated onto malt extract agar (MEA) and potato dextrose agar (PDA) and incubated at $28{ }^{\circ} \mathrm{C} \pm 2$ for 3-4 days. Morphologically different colonies were individually picked up and reinoculated on MEA or/ and PDA for purification [9] and then kept at 4 ${ }^{\circ} \mathrm{C}$ for further study.

Fungal isolated strain was subjected to presumptive identification based on cultural and morphological characteristics, as well molecular identification was conducted based on amplification and sequencing of internal transcribed spacer (ITS) region Genomic was extracted using the protocol of Gene Jet Plant genomic DNA purification Kit (Thermo).

*Corresponding author e-mail: aalfarouk@yahoo.com 
The ITS region was amplified in polymerase chain reaction (PCR) using the genomic DNA as template and ITS primers of ITS1 (5 ' TCCGTAGGTGAACCTGCGG -3') and ITS4 (5 '- TCCTCCGCTTATTGATATGC-3 '). The PCR mixture $(50 \mu \mathrm{L})$ contained Maxima Hot Start PCR Master Mix (Thermo), $0.5 \mu \mathrm{M}$ of each primer, and $1 \mu \mathrm{L}$ of extracted fungal genomic DNA. The PCR was performed in a DNA Engine Thermal Cycler by Sigma Scientific Services Company (Cairo, Egypt) with a hot starting performed at $94^{\circ} \mathrm{C}$ for $3 \mathrm{~min}$, followed by 30 cycles of $94^{\circ} \mathrm{C}$ for $0.5 \mathrm{~min}$, $55^{\circ} \mathrm{C}$ for $0.5 \mathrm{~min}$, and $72^{\circ} \mathrm{C}$ for $1 \mathrm{~min}$, followed by a final extension performed at $72^{\circ} \mathrm{C}$ for $10 \mathrm{~min}$. The commercial sequencing was conducted using ABI 3730x1 DNA sequencer at GATC Company (Germany). The ITS sequence was compared against the GenBank database using the NCBI BLAST program. Sequences were then compared with ITS sequences in the GenBank database using BLASTN.

Extracellular biosynthesis of silver nanoparticles Biomass filtrate of Fusarium keratoplasticum A1-3 preparation

Spore suspension of Fusarium keratoplasticum A1-3 was inoculated in Czapek Dox (CD)[10] as broth media used for fermentation process at $28^{\circ} \mathrm{C}$ for $120 \mathrm{~h}$ in an orbital shaker $(120 \mathrm{rpm})$. The biomass was harvested by passing through four layers of lawn cloth and then washed with sterilized distilled water to remove any media components and about $10 \mathrm{~g}$ of fungal biomass was suspended in $100 \mathrm{~mL}$ distilled water. The mixture was agitated for $72 \mathrm{~h}$ at $28^{\circ} \mathrm{C}$. Finally, the fungal biomass filtrate was obtained by passing it through Whatman filter paper no.1, and then centrifuged at $1000 \mathrm{rpm}$ for $5 \mathrm{~min}$. to sediment any cell debris. This supernatant was used to produce silver nanoparticles[11].

Biosynthesis of AgNPs by biomass filtrate of Fusarium keratoplasticum A1-3

The previously fungal biomass filtrate of Fusarium keratoplasticum A1-3was used for biosynthesis of AgNPs as the following: 1.5 $\mathrm{mM} \mathrm{AgNO}_{3}$ was mixed with $100 \mathrm{~mL}$ of fungal biomass filtrate in a $250 \mathrm{~mL}$ conical flask and incubated at $35{ }^{\circ} \mathrm{C}$ for $48 \mathrm{~h}$, agitated at $150 \mathrm{rpm}$ in dark. Negative controls (Fungal biomass filtrate without $\mathrm{AgNO}_{3}$ solution) were also run along with the experiment. FourmL of each sample was taken and the absorbance was measured at 400 $\mathrm{nm}$ using a UV-vis spectrophotometer (JENWAY 6305 Spectrophotometer).

Egypt.J.Chem. Special Issue (2017)
Characterization of biosynthesized silver nanoparticles

UV-Vis spectroscopy shows specific surface plasmon resonance peak (JENWAY 6305 Spectrophotometer) using to characterize silver nanoparticles. The size and shape of AgNPs were characterized by Transmission Electron Microscopy (TEM - JEOL 1010 Japan). Whilst, the interaction between protein and AgNPs was analyzed by conducting Fourier Transform Infrared Spectroscopy (FTIR) Cary 630 FTIR system model. X-Ray Diffraction patterns for AgNPs were obtained with the XRD- 6000 series, including stress analysis, residual austenite quantitation, crystallite size/lattice strain, crystallinity calculation, materials analysis via overlaid X-ray diffraction patterns Shimadzu apparatus using nickel-filter and $\mathrm{Cu}-\mathrm{Ka}$ target, Shimadzu Scientific Instruments (SSI), Kyoto, Japan. The average crystalline size of the AgNPs was determined using Debye-Scherrer equation:

$$
\mathrm{D}=\mathrm{k} \lambda / \beta \operatorname{Cos} \theta .
$$

Where, D is the average crystalline size (nm), $\mathrm{k}$ is the Scherrer constant with value from 0.9 to 1 , $\lambda$ is the $X$-ray wavelength, $\beta$ is the full width of half maximum and $\theta$ is the Bragg diffraction angle (degrees). The particle size distribution of AgNPs was evaluated using Dynamic Light Scattering (DLS) measurement conducted with a Malvern Zetazier Instrument. Measurements were taken in the range between 0.1 and $1000 \mu \mathrm{m}$. Data obtained were analyzed using Zetasizer software.

Treated cotton fabric by AgNPssynthesized usingFusarium keratoplasticum A1-3

AgNPs loading onto cotton fabric

Cotton fabrics were pre-washed with warm water and dried. Experiments were performed on samples with maximum dimension of $30 \mathrm{~cm}$ $\times 15 \mathrm{~cm}$. Cotton fabric was padded with AgNPs solutions. For the successive treatment of fabric with colloidal silver, the solution was agitated continuously. All samples were immersed in such colloid bath for $1 \mathrm{~min}$ then squeezed to $100 \%$ wet pick up with laboratory pad at constant pressure. Samples were dried at $70{ }^{\circ} \mathrm{C}$ for $3 \mathrm{~min}$, followed by curing at $150{ }^{\circ} \mathrm{C}$ for $2 \mathrm{~min}$. The following treatments were conducted: (1) untreated fabric as a control, (2) fabric treated with AgNPs solution and, (3) AgNPs treated fabric after being subjected to repeated washing cycles of 5 and 15. Laundering was conducted with a machine set for warm water $\left(40-60^{\circ} \mathrm{C}\right)$ containing, $2 \%$ sodium carbonate. After each laundering (45 minutes), the fabrics were tumble dried in a dryer at $80{ }^{\circ} \mathrm{C}$. 
Qualitative assessment of antimicrobial activity of Nanoparticles treated fabric

The antibacterial activity was qualitatively evaluated against gram positive bacteria represented by Staphylococcus aureus ATCC 29213 and Bacillus subtilis NCTC 10400. Gram negative bacteria represented by Pseudomonas aeruginosa ATCC 9027 and Escherichia coli ATCC 8739. Fabric samples of $1 \mathrm{~cm}$ diameters were placed on the surface of Muller Hinton agar plate previously seeded with the tests microorganisms. After $24 \mathrm{~h}$ of incubation, the plates were observed for the zone of bacteriostatic around the fabric sample, where the zone of clearance was measured in millimeter. Negative controls (cotton fabric without loading with AgNPs) was also run along with the experiment.

Quantitative assessment of antimicrobial activity of Nanoparticles treated fabric

The antimicrobial behavior of fabric was evaluated quantitatively against the previous coded test organisms. Squares of $1 \mathrm{~cm}$ of each fabric were prepared in aseptic manner. Each square was placed in a known concentration of microbial suspension (after calculate colony forming unit (CFU) for this suspension), the reduction in microbial colony (CFU) in standard time was measured. The efficiency of the antimicrobial treatment was determined by comparing the reduction in microbial colony of the treated samples with that of control samples expressed as a percentage reduction in standard time. The bacteriostatic activity was evaluated after $24 \mathrm{~h}$ and the percent reduction of bacteria was calculated using the following equation:

$$
\mathrm{R}(\%)=[(\mathrm{A}-\mathrm{B}) / \mathrm{A}] \times 100
$$

Where $\mathrm{R}=$ the reduction rate, $\mathrm{A}=$ the number of bacterial colonies from untreated fabric, and $\mathrm{B}$ $=$ the numbers of bacterial colonies from treated fabric. Negative controls (cotton fabric without loading with AgNPs) was also run along with the experiment.

Scanning Electron microscopy (SEM) for cotton fabrics

SEM was studied using a scanning electron - JSM-5400 instrument (Jeol, Japan). The specimens in the form of fabric were mounted on the specimen stabs and coated with thin film of gold by the sputtering method.

\section{Statistical analysis}

The means of three replications and standard error $(\mathrm{SEr} \pm)$ were calculated for all the results obtained, and the data were subjected to analysis of variance means by sigma plot 12.5 program.

\section{$\underline{\text { Results and Discussion }}$}

Identification of fungal isolate (A1-3)

Fungal isolate of A1-3 showed high potency to produce AgNPs and identification based on cultural and microscope characteristics (Fig. 1A-D)[12]. Amplification and sequencing of ITS region of fungal rDNA resulted in approximately538 bp. The blast-n and pair-wise sequence alignment analysis reveals $98 \%$ identity with the sequences of Fusarium keratoplasticum. Phylogenetic analysis, showed that this fungal strain was designated as Fusarium keratoplasticum A1-3 (Fig. 1E).

Fusarium keratoplasticum A1-3 as a template to biosynthesis of AgNPs

Biosynthesis of AgNPs has been performed successfully using Fusarium keratoplasticum A1-3 through extracellular mechanism. The reduction of AgNPs is usually accompanied with color change from colorless to yellowish brown gradually. Extracellular mechanism depends on the reduction of $\mathrm{Ag}$ ions through bio-reduction agent represented in protein in fungal biomass filtrate. The reduction of $\mathrm{Ag}^{+}$ions is happen when $\mathrm{AgNO}_{3}$ was mixed with biomass filtrate of Fusarium keratoplasticum A1-3 and then the color is gradually changed from colorless to yellowish brown. Whilst, stability of the formed $\mathrm{AgNPs}$ is due to the existence of protein secreted in the filtrate medium. Control sample (biomass filtrate without $\mathrm{AgNO}_{3}$ ) has no color changes during preparation period (Fig. 2).

Characterization of AgNPs synthesis by Fusarium keratoplasticum A1-3

\section{$U V$-Vis Spectroscopy}

The absorption spectra of AgNPs synthesized by Fusarium keratoplasticum A13showedmaximum surface Plasmon Resonance band at $400 \mathrm{~nm}$ (Fig.3-a). The same results were recorded by [1] who found that the absorption spectrum of brown AgNPs synthesis by Aspergillus niger G3-1 showed a surface Plasmon absorption band with a maximum of about $400 \mathrm{~nm}$. 

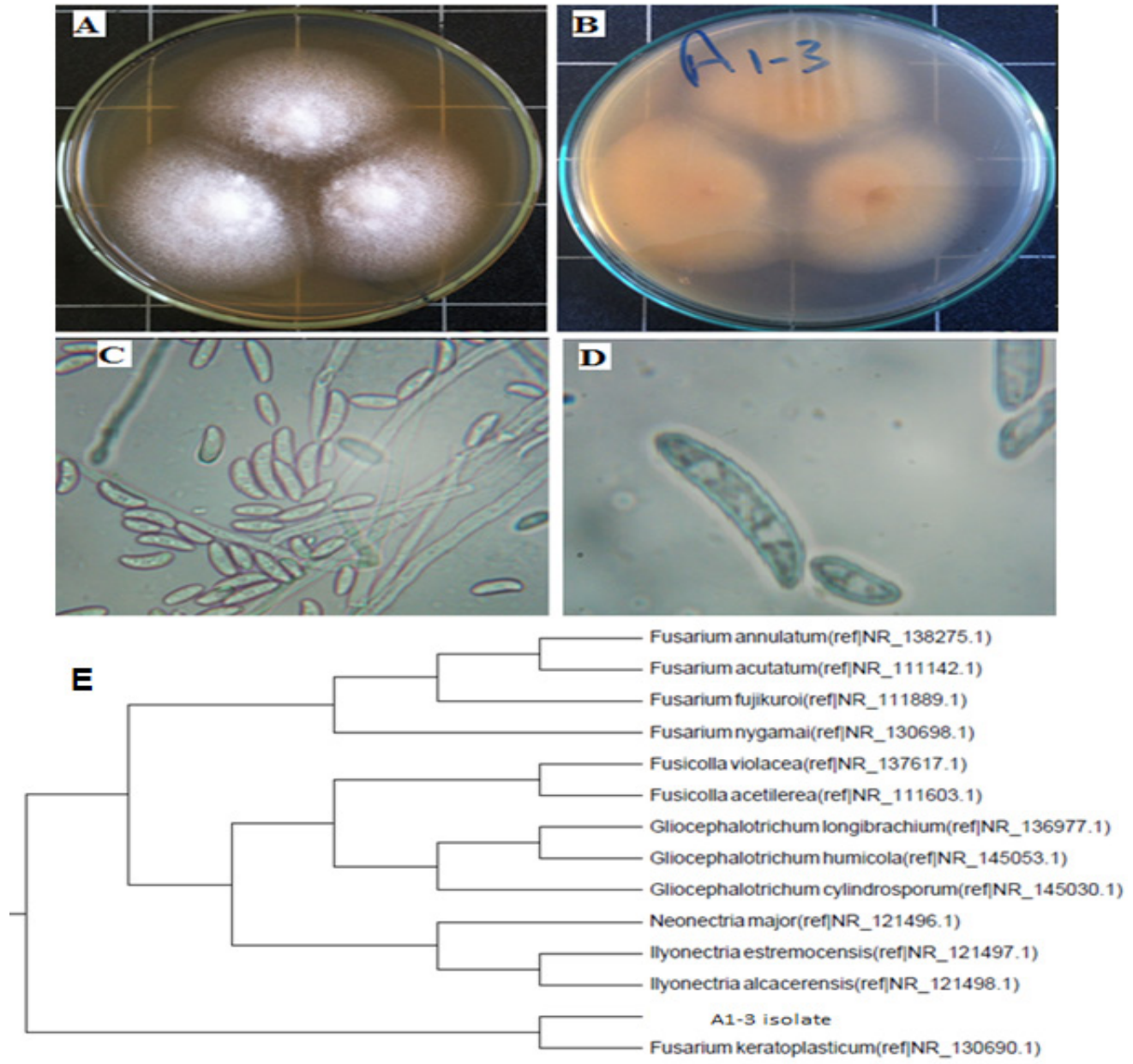

Fig. 1. Identification of fungal isolate A1-3. (A)Colony of fungal isolate A1-3 on MEA, (B)Reverse colony of fungal isolate A1-3, (C) and (D)Bright field microscope $(X=10 \times 40$ and 10x100 respectively) and (E)Phylogenetic analysis of ITS sequences of the fungal isolate A1-3 with the sequences from NCBI and designated as Fusarium keratoplasticum A1-3.

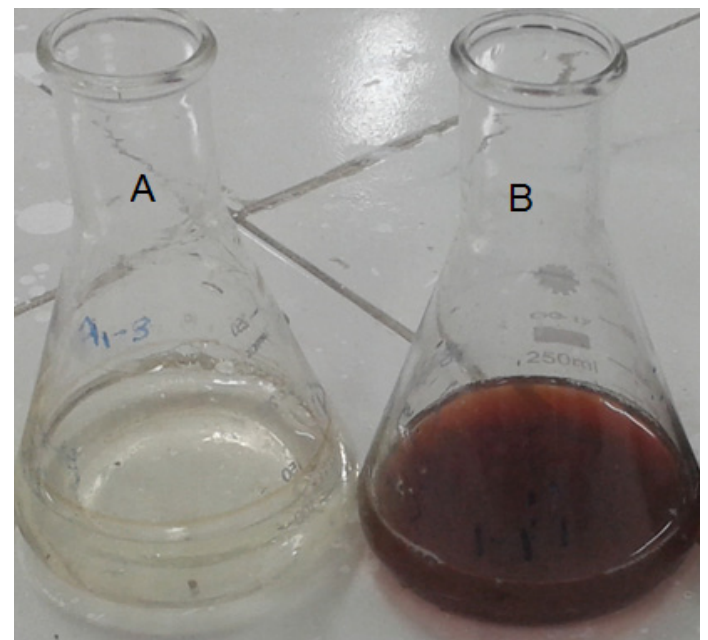

Fig. 2. Color change of biosynthesized AgNPs. (A) Fungal biomass filtrate before addition of $\mathrm{AgNO}_{3}$ and (B) After addition of $\mathrm{AgNO}_{3}$ showing change of color from colorless to brown.

Egypt.J.Chem. Special Issue (2017)
Transmission electron microscope (TEM)

Silver nanoparticles synthesized using Fusarium keratoplasticum A1-3 showed individual AgNPs as well as number of aggregates with spherical in shape for AgNPs which decided by TEM. The size range of AgNPs synthesized by Fusarium keratoplasticum A1-3was (6-36 nm) (Fig.3-b).

\section{Fourier Transform Infrared Spectroscopy (FTIR)}

FTIR spectrums of biosynthesized AgNPs showed characteristic absorption peaks appear at $(3431.50,2923.06,1650.13,1384.09$, $\left.1068.84 \& 547.08 \mathrm{~cm}^{-1}\right)$. The peaks at3431.50 $\mathrm{cm}^{-1}$ corresponds to $\mathrm{O}-\mathrm{H}$ stretching group of phenols and alcohol and may be due to the $\mathrm{N}-\mathrm{H}$ asymmetric stretch mode of amines. The peaks at $2923.06 \mathrm{~cm}^{-1}$ could are due to $\mathrm{C}-\mathrm{H}$ stretch of methylene groups of proteins. The bands at 
$1650.13 \mathrm{~cm}^{-1}$ correspond to the binding vibrations of amide I band of protein with N-H stretching's. The bands observed at 1384.09 and $1068.84 \mathrm{~cm}^{-1}$ can be assigned to $\mathrm{C}-\mathrm{N}$ stretching vibrations of aromatic and aliphatic amines. The peaks at $547.08 \mathrm{~cm}^{-1}$ correspond to alkene ( $=\mathrm{C}-\mathrm{H}$ bending). Proteins present in the extract can bind to AgNPs through either free amino or carboxyl groups in the proteins.

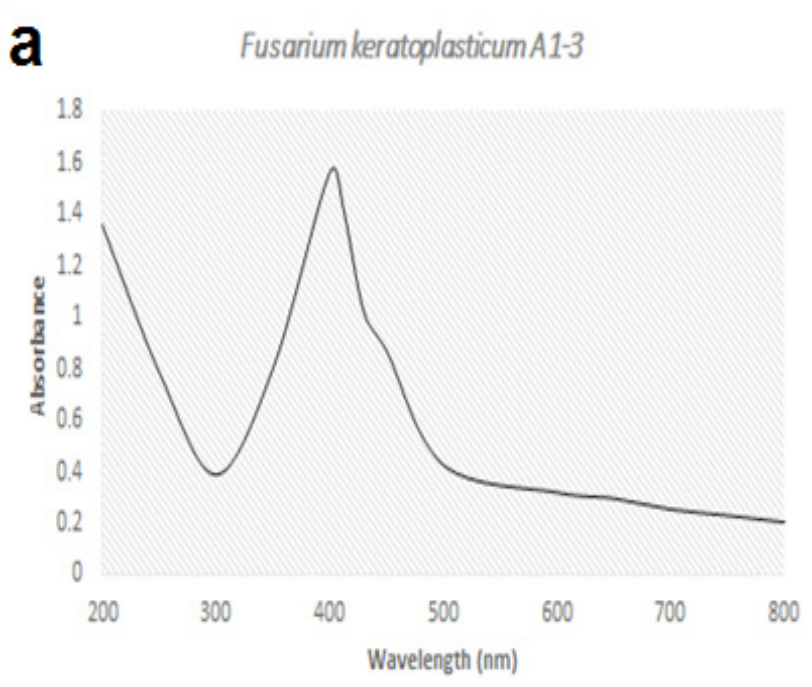

\section{$X$-ray diffraction $(X R D)$ analysis}

$\mathrm{X}$-ray diffraction patterns were carried out to confirm the crystalline nature of the particles. The data obtained from Fig. 5 showed intense peaks corresponding to (111), (200), (220) and (311), which clearly confirms the formation of silver nanoparticle synthesized by Fusarium keratoplasticum A1-3 were essentially in the face centered cubic structure and crystal in nature which agreement with Mohmed A.A. et al. [13].

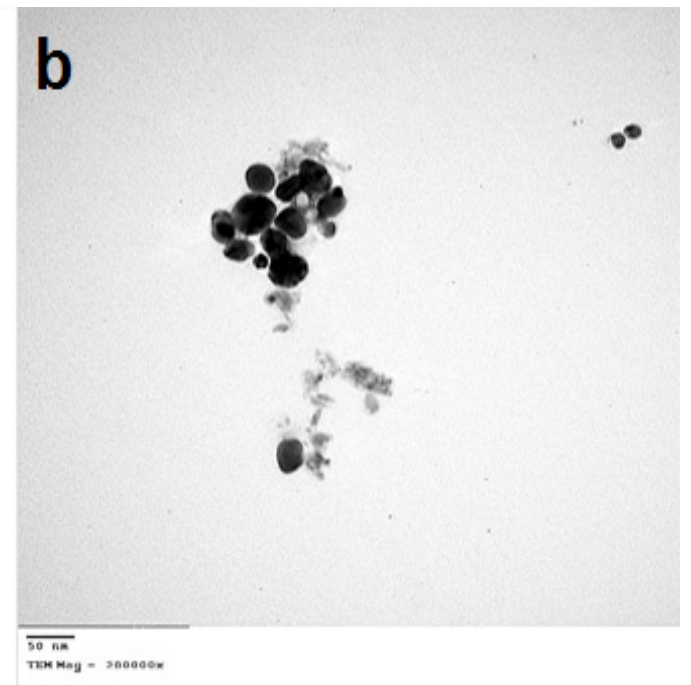

Fig. 3. A- UV spectrum of AgNPssynthesized by Fusarium keratoplasticum A1-3. b- TEM image of AgN Pssynthesized by Fusarium keratoplasticum A1-3.

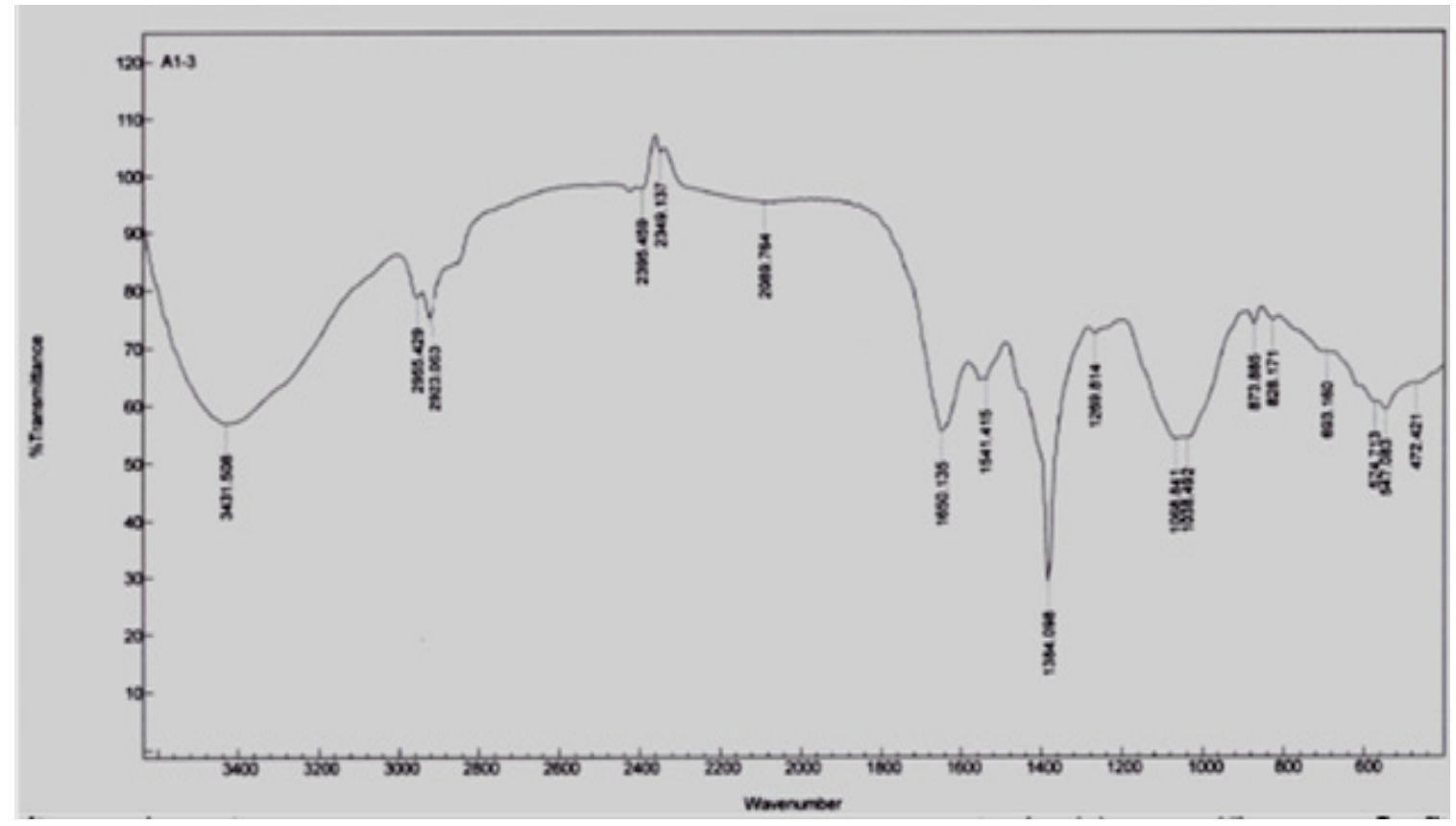

Fig. 4. FTIR spectra showing the presence of proteins as capping agents for AgNPs synthesized by Fusarium keratoplasticum A1-3. 


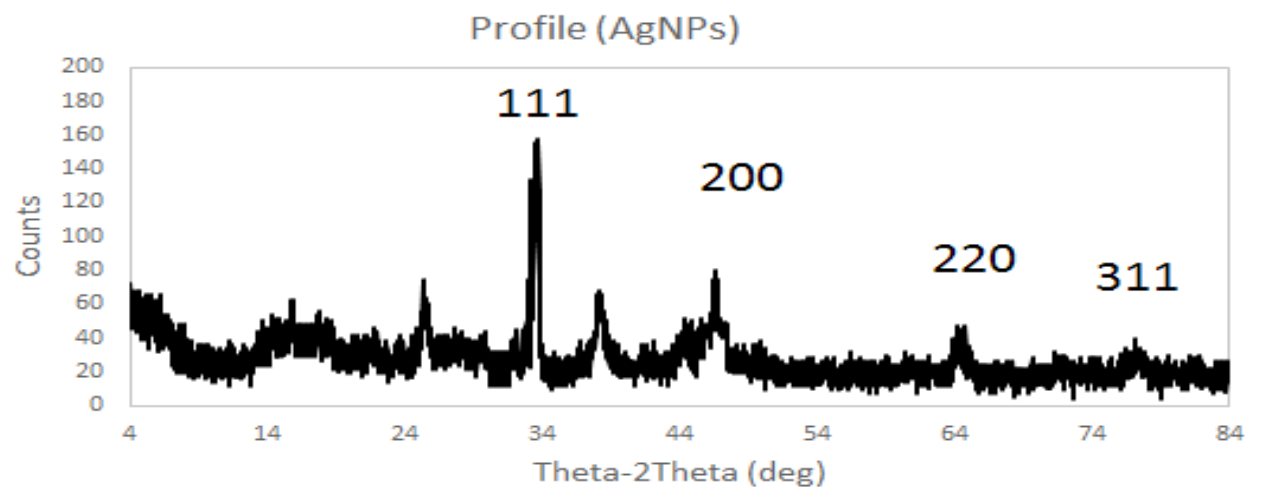

Fig. 5. XRD pattern of AgNPs synthesized by Fusarium keratoplasticum A1-3.

Particle size analysis and zeta potential

The particle size determination of the formulated silver nanoparticle was based on intensity (Fig. 6). Laser diffraction revealed that the particles obtained were poly dispersed mixture. The AgNPs synthesized by Fusarium keratoplasticum A1-3 showed the average diameter of the particles was found to be 54.33 $(92.7 \%)$ with Zeta potential $(\mathrm{mV})-23$.

\section{Cotton fabric treated with biosynthesized AgNPs}

Loading of cotton fabric with silver nanoparticles

Cotton fabric sample was immersed in the biomass filtrate of Fusarium keratoplasticum A1-3 containing the AgNPs for 1 min followed by squeezing to a wet pick up 100 then drying at $80{ }^{\circ} \mathrm{C}$ for $3 \mathrm{~min}$ and finally placing in an oven at $150{ }^{\circ} \mathrm{C}$ for $2 \mathrm{~min}$. Figure 7 showed the scanning electron microscope (SEM) of treated cotton fabric with AgNPs and blank cotton (Untreated) samples.

Scanning electron microscope image of treated cotton fabric showed the presence of AgNPs deposited on the surface of the fabric. Also, AgNPs dispersed homogeneously over the surfaces of cotton fabric. While, the blank sample exhibited a very smooth surface. In addition, chemical composition of the treated cotton fabric with AgNPs were analyzed by Energy Dispersive X-ray spectrometer (EDX). From EDX, the percentage of Ag nanoparticles loaded on the surface of treated fabric reached $1 \%$ with weight percent reaches $0.39 \%$. These results showed that, the successfully and forcefully attached of silver nanoparticle with the surface of treated cotton fabric.

Qualitative and quantitative assessment of antimicrobial activity of treated cotton fabric

Through the qualitative and quantitative methods to determine the antimicrobial activity of the treated cotton fabric before and after washing cycles. Typically, clear zone and microbial reduction percentage are two methods which usually used to evaluate the antimicrobial activity and follow up the fabrics washing durability.

Paladini et al. reported that, the antibacterial activity would be labeled as "good" when inhibition zone to bacterial proliferation is larger than $1 \mathrm{~mm}$. Whilst, the antibacterial activity of the sample is "insufficient" in case of the sample is totally colonized by bacteria. Unless, a free bacterial zone shown merely under the surface of sample, it can be labeled as a "sufficient" antibacterial activity. So that, from Table 1 it could be decided that, the treated cotton fabric samples with AgNPs before washing exhibited a good antimicrobial against Gram positive bacteria represented by $S$. aureus \& B. subtilis and Gram negative bacteria represented by $P$. aeruginosa \& E. coli. It is also declared that, the diameter of inhibition zone around treated cotton fabric was correlated with number of washing cycles. Therefore, the repeated washing cycles for treated cotton fabric decreased the inhibition zone.

Table 2 showed that, the antimicrobial reduction percentage of treated fabric before washing lied in the range of $86 \%-93 \%$ with respect to the pathogenic microbe. These percentages are due to the presence of AgNPs loaded with the cotton fiber. Upon washing the physically bonded of AgNPs on the surface of cotton fabric became unbounded so that, the antimicrobial reduction percentages were decreased. The binder (e.g. acrylate cross-linker) could be further added to the finishing bath with AgNPs to overcome the loss in the antimicrobial activity of treated cotton fabric. 
Size Distribution by Intensity

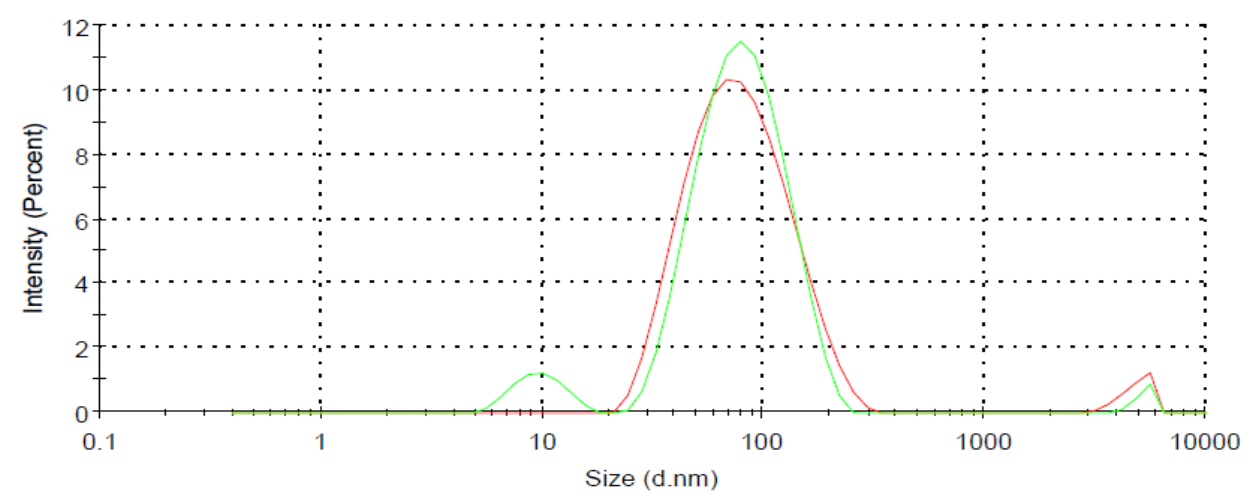

Fig. 6. Particle size distribution for AgNPs synthesized by Fusarium keratoplasticum A1-3.

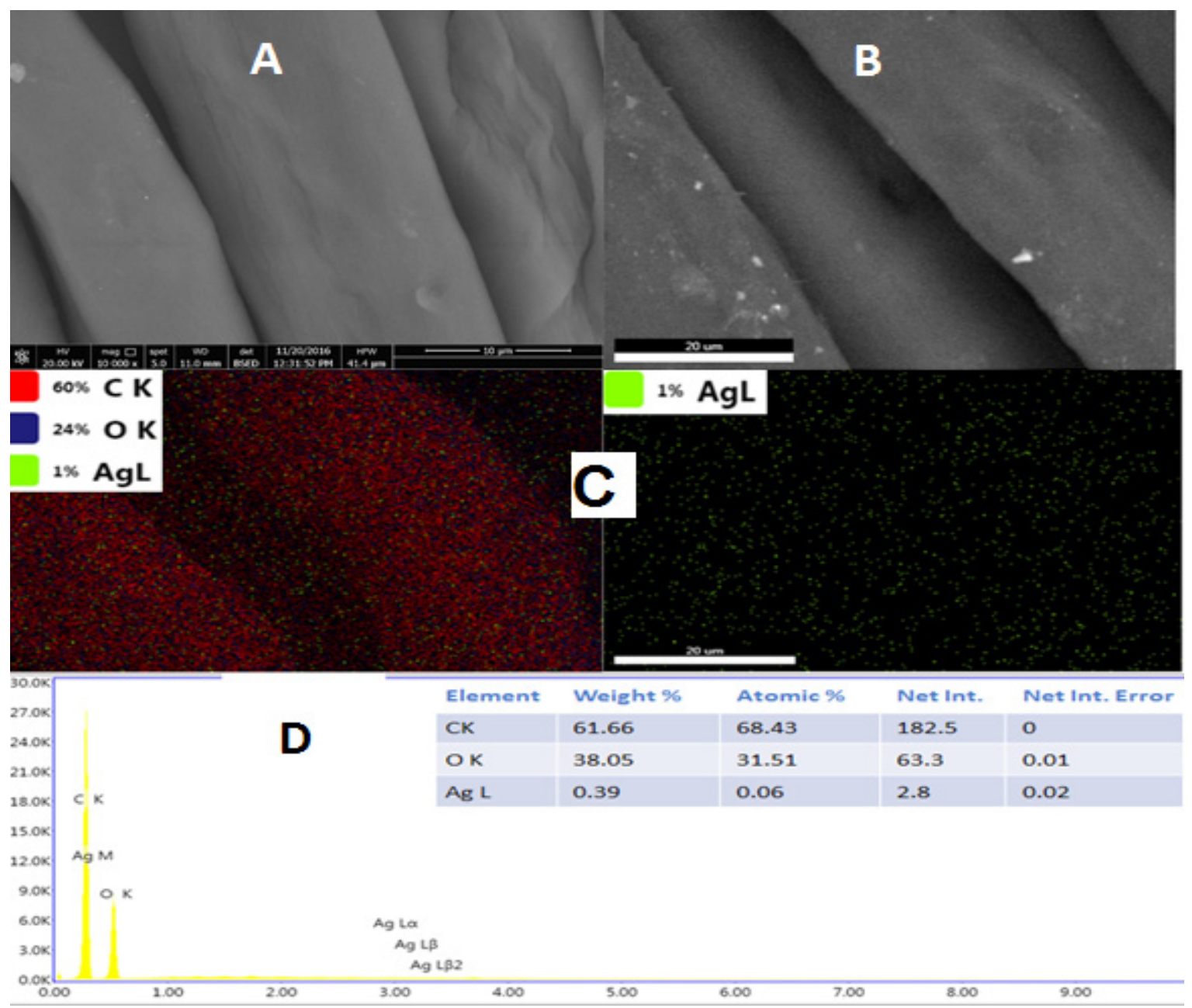

Fig. 7. SEM images A) untreated cotton fabric with AgNPs; B) treated cotton fabric with AgNPs; C) mapping picture of the surface of treated fabric with AgNPsand D) EDX of treated sample with elemental analysis of the AgNPs contents. 
TABLE 1. Effect of AgNPs synthesized by Fusarium keratoplasticum A1-3 on Cotton Fabrics by clear zone method (Qualitative method).

\begin{tabular}{lcccc}
\hline $\begin{array}{c}\text { Number of } \\
\text { washing cycles }\end{array}$ & \multicolumn{4}{c}{ Nano-sized silver colloids concentration (100 ppm) } \\
\hline Before washing & $1.6 \pm 0.07 \mathrm{~mm}$ & $1.8 \pm 0.05 \mathrm{~mm}$ & $1.2 \pm 0.02 \mathrm{~mm}$ & $1.3 \pm 0.03 \mathrm{~mm}$ \\
After 5 cycles & $0.9 \pm 0.02 \mathrm{~mm}$ & $1.1 \pm 0.04 \mathrm{~mm}$ & $0.9 \pm 0.03 \mathrm{~mm}$ & $0.9 \pm 0.02 \mathrm{~mm}$ \\
After $\mathbf{1 5}$ cycles & $0.7 \pm 0.03 \mathrm{~mm}$ & $0.767 \pm 0.02 \mathrm{~mm}$ & $0.6 \pm 0.02 \mathrm{~mm}$ & $0.6 \pm 0.05 \mathrm{~mm}$ \\
\hline \multicolumn{2}{c}{ Negative control was cotton fabric without loading with AgNPs and washed for 5 and 15 cycles and wasn't showed any clear zone. }
\end{tabular}

TABLE 2. Effect of repeated washing for treated cotton fabric with AgNPs on the antibacterial properties by Quantitative method.

\begin{tabular}{lcccc}
\hline \multirow{2}{*}{$\begin{array}{c}\text { Number of } \\
\text { washing cycles }\end{array}$} & \multicolumn{4}{c}{ Bacterial reduction (\%) } \\
& S. aureus & B. subtilis & P. aeruginosa & E. coli \\
\hline Before washing & $91.9 \pm 0.3 \%$ & $93.8 \pm 0.2 \%$ & $86.2 \pm 0.1 \%$ & $86.2 \pm 0.3 \%$ \\
After $\mathbf{5}$ cycles & $70.9 \pm 0.4 \%$ & $71.9 \pm 0.2 \%$ & $64.3 \pm 0.2 \%$ & $64.1 \pm 0.3 \%$ \\
After $\mathbf{1 5}$ cycles & $49.9 \pm 0.3 \%$ & $53.9 \pm 0.2 \%$ & $42.3 \pm 0.3 \%$ & $43.4 \pm 0.3 \%$ \\
\hline $\begin{array}{l}\text { Negative control was cotton fabric without loading with AgNPs and washed for 5 and } 15 \text { cycles and wasn't showed any } \\
\text { antimicrobial reduction percentages. }\end{array}$
\end{tabular}

\section{Conclusion}

Silver nanoparticles were successfully biosynthesized using Fusarium keratoplasticum A1-3. The biosynthesis of nanoparticles by Fusarium keratoplasticum A1-3 is very cheap and effective without the involvement of hazardous chemicals. The color change happened due to surface plasmon resonance during the reaction which was characteristics by UV-vis spectroscopy. XRD confirms face centered cubic crystal structure, TEM determined the shape and size of AgNPs and FTIR study ensure that functional groups have played role in bio-reduction of silver ions to silver metal in nano sized and responsible for the stability of nanoparticles in colloidal. Finally, the results reported in this study could be useful in application of biosynthesized AgNPs in textile industry open innovative approach for enhancement the properties of treated textile.

\section{References}

1. Fouda A., Elgamal M.S., Hassan S., Salah S., Salem S.S. and Shaheen T.I., Facile approach towards medical textiles via myco-synthesis of silver nanoparticles. Der Pharma Chemica (2017).
2. El-Rafie M., Shaheen T., Mohamed A. and Hebeish A., Bio-synthesis and applications of silver nanoparticles onto cotton fabrics. Carbohydrate Polymers; 90 (2012).

3. Fouda A. and Shaheen T.I., Silver nanoparticles: biosynthesis, characterization and application on cotton fabrics. Microbiology Research Journal International 20,14 (2017).

4. Hebeish A., El-Rafie M., El-Sheikh M., Seleem A. and El-Naggar M., Antimicrobial wound dressing and anti-inflammatory efficacy of silver nanoparticles. Int J Biol Macromol; 65 (2014).

5. El-Rafie M., Mohamed A., Shaheen T.I. and Hebeish A., Antimicrobial effect of silver nanoparticles produced by fungal process on cotton fabrics. Carbohydrate Polymers 80, 77982. (2010).

6. Pankaj K.T., Review article: production of metal nanoparticles from biological resources. Int $J$. Curr Microbiol App Sci 5. (2016)

7. Dhillon G.S., Brar S.K., Kaur S. and Verma M., Green approach for nanoparticle biosynthesis by fungi: current trends and applications. Critical 
Reviews in Biotechnology; 32 (2012).

8. Navin J., Arpit B., Sonali M., Tarfdar J.C. and Jitendra P., Extracellular biosynthesis and characterization of silver nanoparticles using Aspergillus flavus NJP08; A mechanism perspective. Nanoscale 3 (2011).

9. Fouda A., Khalil A., El-Sheikh H., AbdelRahman E. and Hashem A., Biodegradation and detoxification of bisphenol by filamentous fungi screened from nature. Jof Advance in biology and

10. Zahran M., Mohamed A., Mohamed F. and ElRafie M., Optimization of biological synthesis of silver nanoparticles by some yeast fungi. Egypt $J$ Chem. 56 (2013).

11. Fouda A., Saad E., Elgamal M.S., Mohmed A.A., and Salem S.S., Optimal factors for biosynthesis of silver nanoparticles by Aspergillus sp. Al Azhar
Bulletin of Science, Conf, March 2017;9th.(2017).

12. Cappuccino J.G. and Sherman N., Microbiology: A Laboratory Manual. Dorling Kindersley Pvt Ltd, New Delhi, India 143 (2007).

13. Mohmed A.A., Saad D., Hassan S., Fouda A., Elgamal S.M. and Salah Salem S., Extracellular biosynthesis of silver nanoparticles using aspergillus sp. And evaluation of their antibacterial and cytotoxicity. Journal of Applied Life Sciences International (2017).

14. Paladini F., Picca R., Sportelli M., Cioffi N., Sannino A. and Pollini M., Surface chemical and biological characterization of flax fabrics modified with silver nanoparticles for biomedical applications. Materials Science and Engineering 50, 10 (2015).

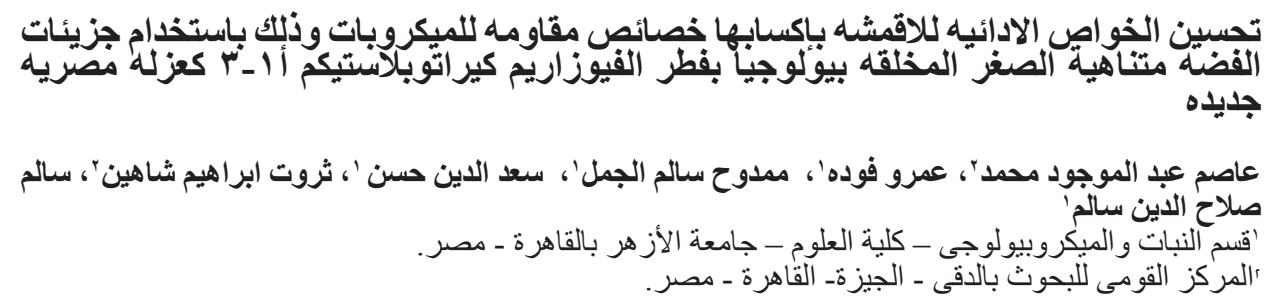

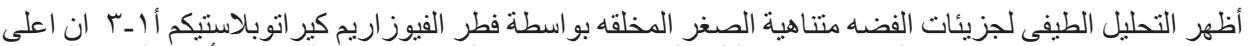

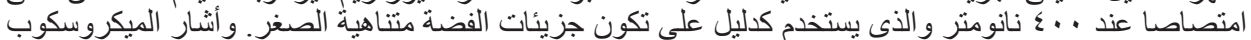

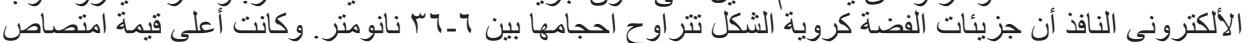

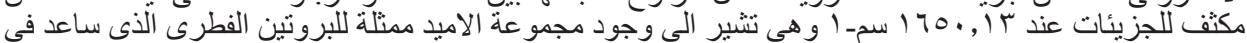

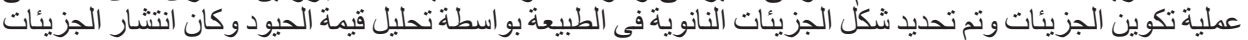

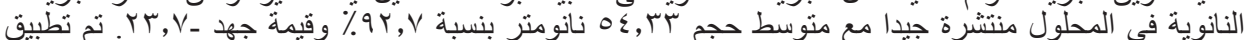

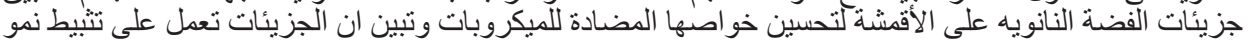

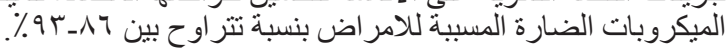




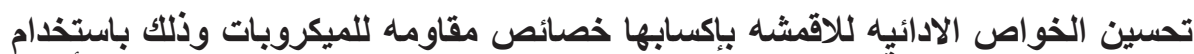

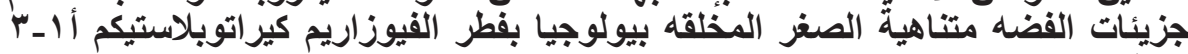
كعزلنه مصريـات جديده مناه

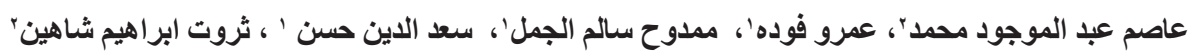

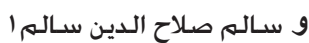

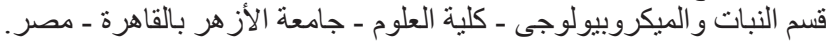

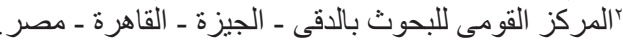

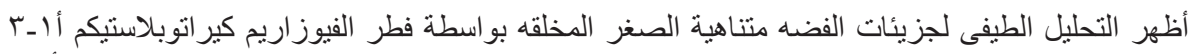

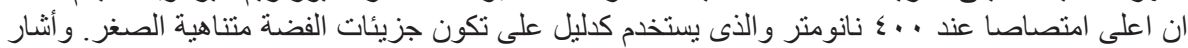

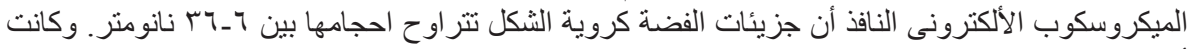

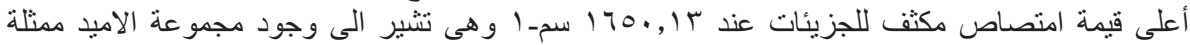

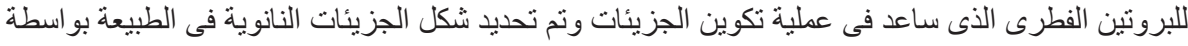

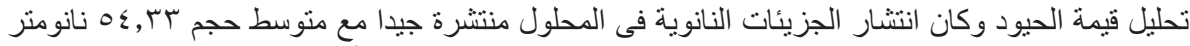

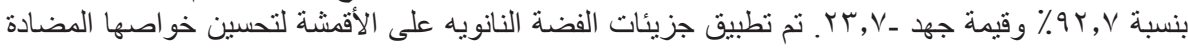

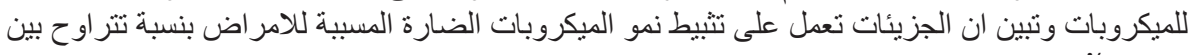

